\title{
Development and Performance Evaluation of Eco-Friendly Crab Shell Powder Based Brake Pads for Automotive Applications
}

\section{Lenin Singaravelu ${ }^{1 *}$, Rahul Ragh M. ${ }^{1}$, Vijay R. ${ }^{1}$, S. Manoharan ${ }^{2}$ and Mohamed Kchaou ${ }^{3}$}

\author{
${ }^{1}$ Department of Production Engineering, National Institute of Technology, \\ Tiruchirappalli, Tamil Nadu, India \\ ${ }^{2}$ Department of Mechanical Engineering, SSM College of Engineering, \\ Komarapalayam, Tamil Nadu, India \\ ${ }^{3}$ Department of Mechanical Engineering, University of Sfax, ENIS, LASEM, Sfax, \\ Tunisia \\ *Email: dlenin@nitt.edu
}

\begin{abstract}
The present study deals with the effective usage of crab shell, which is a solid waste in the seafood industry. The crab shell was powdered and treated with chemicals to obtain the chemically treated crab shell powder. The crab shell was powdered and heated to the desired conditions to obtain thermally processed crab shell powder. These two powders so obtained were used with other ingredients in the development of brake pads. For comparison crab shell powder free brake pads were also developed. The developed brake pads were tested for various characteristics as per the industrial standards. Thermal stability was found using Thermogravimetric analysis. The fade and recovery behaviours were estimated for the developed brake pads using Chase test following IS2742 Part-4. The test results indicate that the thermally processed crab shell powder based brake pads showed better thermal stability with a char residue of $37 \%$, while the chemically treated crab shell powder based brake pads had better fade and recovery characteristics with a fade rate of $1.71 \%$ and recovery rate of $99.86 \%$ due to its better heat dissipation and coarse structure. Scanning electron microscopy paved the way to study the worn characteristics of the Chase tested samples. An extensive evaluation method was used to rank the developed brake pads based on the Chase test performance; it also ranked chemically treated crab shell powder-based brake pads as the best performer.
\end{abstract}

Keywords: Thermally processed crab shell powder; chemically treated crab shell powder; brake pad; thermal stability; Chase test

\section{INTRODUCTION}

The brake is a mechanical component used to convert kinetic energy to thermal energy by friction. Friction is generated by the contact of friction material with the mating surface, which may be liner and drum or brake pad and disc [1]. Brake materials are generally classified as organic, metallic and ceramic. Organic brake materials are further classified into low-metallic and semi-metallic based on the percentage of metallic contents in its composite formulation. Brake friction materials consist of 10-15 ingredients classified as binders, reinforcement fibres, friction modifiers and fillers [2,3]. Binders are used to bind other ingredients together by forming a matrix. Reinforcement fibres provide strength to friction materials; not only mechanical strength; sometimes it 
enhances its thermal as well as tribological behaviour. Friction modifiers are used to vary friction that may be a lubricant which reduces friction and wear (or) abrasive, which enhances friction. Fillers are added to enhance a particular function or reduce cost. Fillers are further categorised as functional fillers and inert fillers [4,5]. Fillers are added to friction material to reduce overall cost, improve manufacturability and impart certain properties.

In earlier stages, asbestos was predominantly used in friction materials industries but was banned in 1989, due to its toxic nature. It had some vital properties like insulation, thermal stability and cost-effectiveness. The reduction of copper and its alloys percentage in the friction material formulations are made by Canada and Washington since 2010. As wear debris of the friction material upon braking which is washed away by the rainwater is hazardous to aquatic life and greatly affects the food chain, So, its usage was reduced to 5 percent in 201 , and it will be 0.5 percent in 2020 [6,7]. Since then, researchers have been working on toxic free ingredients. In the current context, the usage of organic and naturally occurring ingredients in friction composite development is on. Yawas et al. [8] developed an asbestos-free brake pad using a periwinkle shell of various particle sizes ranging from 710 to 125 microns. The developed samples were tested for their physical, mechanical and tribological (pin on disc) properties. The results showed that 125 microns periwinkle brake pads showed better results in all aspects. Aigbodion et al. [9] investigated the effect of various sieve size particles (five different particle sizes) of bagasse on the tribological behaviour of brake pads. It was concluded that 100 microns bagasse filled brake pad showed good results and could meet the properties of conventional brake pads. Ibhadode and Dagwa [10] developed friction materials using palm kernel shell (PKS) along with additional ingredients. The optimal formulation and manufacturing parameters for the development of friction materials was achieved using the Taguchi optimisation technique. PKS pads showed pad wear at vehicular speeds beyond $80 \mathrm{kmph}$. Based on the results, it was suggested that palm kernel shell could replace the role of asbestos in friction lining materials. Sutikno et al. [11] produced carbonised coconut char powder and magnesium oxide-based friction materials for automotive brake materials. Coconut char and magnesium oxide powders were used in the mixing. The tested composites showed coconut char powder-based composites could be effectively used for friction applications as the carbon developed from the coconut char could perform the role of graphite in the composite efficiently.

Idris et al. [12] developed new brake pads using banana peel to replace asbestos. The brake pads were developed at intervals of $5 \mathrm{wt} . \%$ from 5 to $30 \mathrm{wt} \%$. The developed brake pads were tested for physical, mechanical and wear properties. The results showed that $25 \mathrm{wt} . \%$ of uncarbonized and $30 \mathrm{wt} . \%$ of carbonized banana peel powder samples possessed superior properties in all aspects. Akincioglu et al. [13] experimentally investigated the effect of the hazelnut shell and boron oxide dust in brake pads and compared it with commercial pads. The sample with hazelnut shell dust had better properties in all aspects. Thus, by effectively utilising these materials, there is a good reduction in the overall cost and enhancement of its eco-friendly nature. But, aquatic wastes from the sea are a major threat to coastal areas which lead to accumulation causing difficulties in living there. Crab shells, a major solid waste in coastal areas is treated properly and can be used as a filler in brake friction composites advantageously as they mainly constitute calcium carbonate and chitin biopolymer. Presently, CBS powders are used to absorb heavy materials, chitin and chitosan fibres preparation [14].

In an earlier study, CBS powder was processed chemically; its weight percentage was compensated with the weight percentage of palm kernel shell powder and used as 
natural fillers in friction composites. Test results showed that the friction composite containing a higher amount of CBS powder had better performance characteristics [15]. But the processing of crab shell using chemicals consumes more than 24 hours making it time-consuming. The cost incurred is also comparatively high due to the usage of chemicals. The purpose of crab shell processing is to remove fat, protein, and other organic components. The current study focuses on the process of removal of organic components from the CBS and to utilise it in the brake pad formulation. Thus, the present study deals with the development of three different brake pads possessing thermally processed crab shell powder, chemically treated crab shell powder and crab shell powder free specimen. The developed composites were characterised for physical, chemical, thermal, mechanical and tribological properties.

\section{MATERIALS}

Crab used in the present study is scientifically known as Portunus sanguinolentus, which belongs to the Portunus crab family. It is also commonly known as Blood-spotted swimmer crab (three spot crab). The crab shells were procured from local seafood dealers across the coastal regions of Chennai, Tamil Nadu, India $\left(13.0827^{\circ} \mathrm{N}, 80.2707^{\circ} \mathrm{E}\right)$. They were washed in distilled water, and ground finely using a mortar and sieved in a range of 200-250 BSS (British Sieve Size). Friction material manufacturer's internal reference standard was followed for sieving the powders. The sieved powder was immersed in a solution of chloroform and methanol (with 2:1 ratio) at room temperature for an hour to remove fat. Further, the crab shell powder was immersed in five wt.\% of sodium hydroxide solution for twenty-four hours for deproteination. Finally, the powder was treated with four wt.\% of Hydrochloric acid solution for an hour for decarbonation. It was then filtrated and dried at room temperature to get the final powder. Thus, the complete crab shell powder was successfully processed without any organic compounds, with the help of chemical reagents [16].

Another simple method to remove all organic compounds is when subject into heat. The thermally processed crab shell powder was produced based on the procedure as follows. The crab shell collected was cleaned in distilled water to remove dirt. The cleaned crab shell was dried for 48 hours at room temperature conditions. The dried crab shell was crushed and heated in a crucible furnace at a temperature of $300^{\circ} \mathrm{C}$ for 15 minutes. Finally, it was ground in a mortar until it was converted to powder then sieved in a range of 200-250 BSS using standard brass sieves. The sieve was considered in that range as it is an optimal size range used as per standard industry practice. The properties of chemically treated and thermally processed CBS powders are shown in Table 1 that were analysed to provide the general specifications of varying key ingredients.

In Table 1, the density was measured as per the Archimedes principle, the appearance was as per visual method, the structure was based on the sieve and SEM analysis, while the thermal weight loss was found using TGA. Figure 1 (a) shows the chemically treated CBS powder, which has coarse particle size and shape compared to Figure 1(b) thermally processed CBS powder. Chemically processed CBS powder has some rough surface useful for better adhesion to the matrix. The thermally processed CBS powder has some slight agglomeration which could be due to its slight fine size. 
Table 1. Properties of chemically treated and thermally processed CBS powder.

\begin{tabular}{lcccc}
\hline $\begin{array}{l}\text { S. } \\
\text { No. }\end{array}$ & Properties & Unit & $\begin{array}{c}\text { Chemical treated } \\
\text { CBS powder }\end{array}$ & $\begin{array}{c}\text { Thermal processed } \\
\text { CBS powder }\end{array}$ \\
\hline 1 & $\begin{array}{c}\text { Density at room } \\
\text { temperature }\end{array}$ & $\mathrm{kg} / \mathrm{m}^{3}$ & 2060 & 2110 \\
2 & $\begin{array}{c}\text { Appearance } \\
\text { Structure ( from SEM } \\
\text { appearance, sieve } \\
\text { analysis) }\end{array}$ & Colour & Pale white colour & $\begin{array}{c}\text { Grey colour } \\
\text { Finer } \\
3\end{array}$ \\
$\begin{array}{c}\text { Thermal weight loss at } \\
\text { the end of } 800^{\circ} \mathrm{C}\end{array}$ & $\%$ & $\begin{array}{c}\text { Little coarse (200 } \\
\text { BSS- 95\% pass) }\end{array}$ & $\begin{array}{c}\text { (250 BSS- 97\% } \\
\text { pass) }\end{array}$ \\
4 & & 56.81 & 43.01 \\
\hline
\end{tabular}

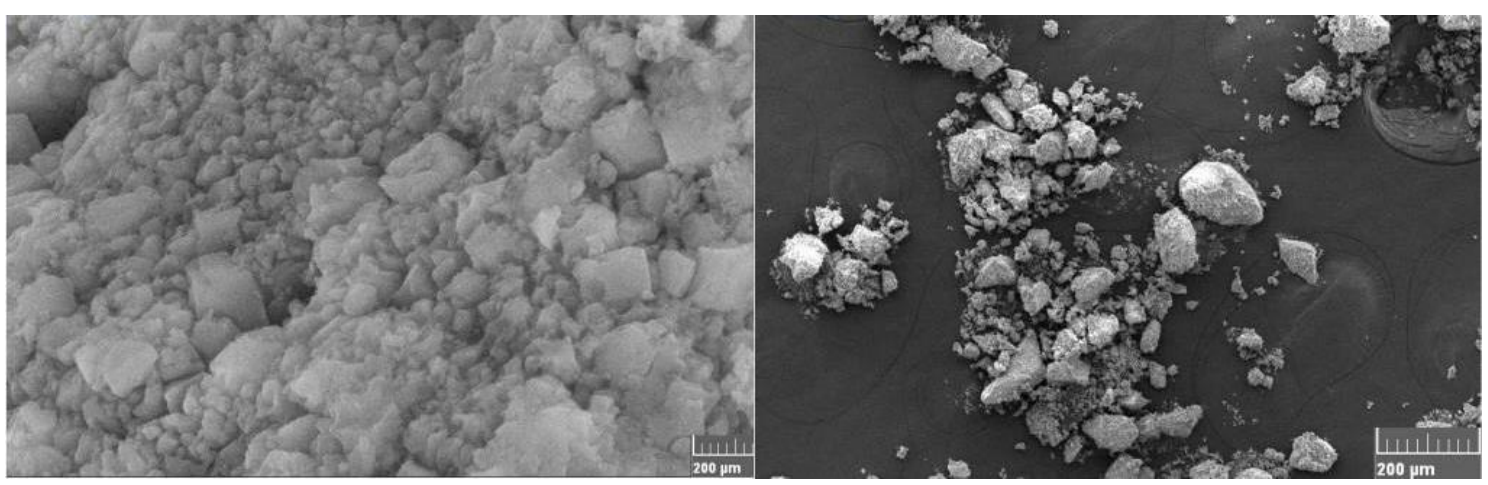

(a)

(b)

Figure 1. SEM images of (a) chemically treated and; (b) thermally processed CBS powder.

\section{DEVELOPMENT AND CHARACTERISATION OF BRAKE FRICTION COMPOSITES}

\section{Development of Composites}

The developed friction composites consist of thirteen ingredients (inclusive of varying ingredients) namely fibres with additives: aramid fibre, steel fibre, friction modifiers: molybdenum-di-sulphide, natural graphite, alumina powder; binders with additives: alkyl benzene modified resin, NBR, sulphur, fillers (functional): tin powder, cashew friction dust, vermiculite, fillers (inert): synthetic barites. These materials is a cumulative of 88 wt.\% was used parental ingredients. The rest of the $12 \mathrm{wt} . \%$ was of thermally processed and chemically treated CBS powder, which is a functional filler. Based on the varying ingredients, the chemically treated and thermally processed CBS powder, the developed friction composites were named as NAO1, NAO2 respectively. For comparison, another brake pad was developed without crab shell powder, in which the wt $\%$ of crab shell powder was compensated with synthetic barites additionally and designated as NAO3.

The methodology involved in manufacturing the friction composites is weighing, mixing, curing, post curing and finishing. The details of the processes are given in Table 2. In mixing, it was done in a plough shear mixer possessing three choppers and one shovel rotating at 3000 and $140 \mathrm{rpm}$ respectively. The mixing sequence involved in the present study is given in Table 3. Curing was done on a compressing moulding machine 
that has eight-cavity die, and where condensation polymerisation occurs in this process, intermittent breathings were given to remove gases evolved during the process. Post curing was done to remove residual stress formed during the curing. This process also helps to further cure some uncured resins in the curing stage. The finishing operation involves grinding using a belt grinder to get the required thickness $(15 \mathrm{~mm})$ while the centre cut was given using the diamond wheel cutter. The developed brake pads that were made as per the standard size that could fit in an Indian vehicle are given in Figure 2.

Table 2. Procedure and conditions involved in the development of friction materials.

\begin{tabular}{|c|c|c|}
\hline S.No. & Procedure & Conditions \\
\hline 1 & $\begin{array}{l}\text { Sequential mixing } \\
\text { in plough-shear mixer } \\
\text { (Lodigee mixing } \\
\text { machine) }\end{array}$ & $\begin{array}{c}\text { Total duration } 20 \text { minutes shovel speed } 140 \mathrm{rpm} \text {, } \\
\text { cutter speed } 3000 \mathrm{rpm} \text { and } 3 \mathrm{~kg} \text { mix was prepared. } \\
\text { Sequence of mixing was (a) fibres (b) powdery } \\
\text { ingredients (c) binders }\end{array}$ \\
\hline 2 & Curing & $\begin{array}{l}\text { Compression moulding machine with } 8 \text { cavities, } \\
\text { Temp. } 145^{\circ} \mathrm{C} \text {; Compression Pressure } 13 \mathrm{MPa} \text {; each } \\
\text { cavity was filled with approximately } 70 \text { grams of } \\
\text { the mixture } \\
\text { Curing time: } 7 \text { minutes (curing time: thickness of } \\
\mathrm{pad} / 2)\end{array}$ \\
\hline 3 & Post- curing & $\begin{array}{l}\text { (Step baking process) } \\
140^{\circ} \mathrm{C} \text { to } 160^{\circ} \mathrm{C}-3 \text { hours } \\
\text { at } 160^{\circ} \mathrm{C}-2 \text { hours } \\
160^{\circ} \mathrm{C} \text { to } 165^{\circ} \mathrm{C}-0.5 \text { hours }\end{array}$ \\
\hline 4 & Finishing & $\begin{array}{l}\text { Grinding was done to remove the resin layer and } \\
\text { burs, and a centre cut was given to enhance air } \\
\text { circulation during braking as well as to remove } \\
\text { worn debris during braking }\end{array}$ \\
\hline
\end{tabular}

Table 3. Sequence of mixing.

\begin{tabular}{lcc}
\hline S.No. & Mixing sequence & Time in minutes \\
\hline 1 & $\begin{array}{c}\text { Aramid fibre, steel fibre } \\
\text { Vermiculate, molybdenum-di-sulphide, natural graphite, } \\
\text { tin powder, alumina powder, synthetic barites*, cashew } \\
\text { friction dust, thermally processed* / chemically treated } \\
\text { CBS powder* }\end{array}$ & 6 \\
3 & Alkyl benzene modified phenolic resin, NBR, sulphur & 40 \\
\hline
\end{tabular}

*varying ingredient depending on the composite

\section{Thermal Stability Test}

Thermal stability plays an important role in deciding the thermal behaviour of the material. Thermal stability was found using the thermogravimetric analyzer (TGA) in an air environment. Five milligrams of sample was used. The temperature was ranging from normal room temperature to $800^{\circ} \mathrm{C}$ (with $10^{\circ} \mathrm{C} / \mathrm{min}$ heat rate) and having a gas flow of $20 \mathrm{ml} / \mathrm{min}$ was used. 


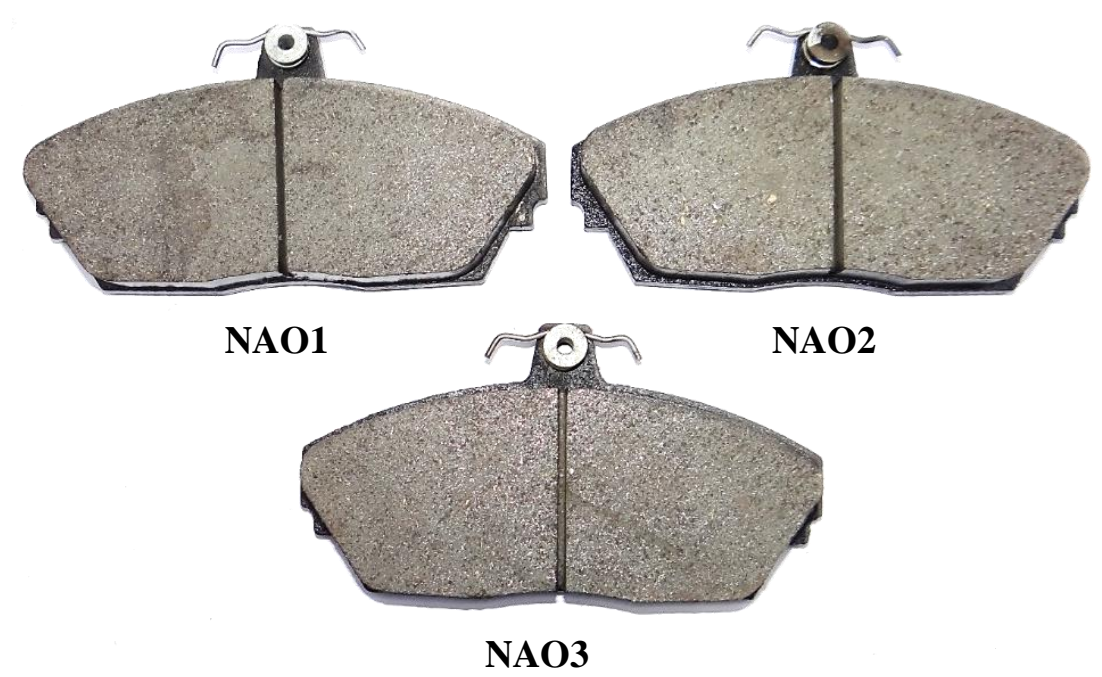

Figure 2. Developed brake pads

\section{Physical, Chemical, Mechanical and Thermal Characterisation}

The physical, chemical, mechanical and thermal characteristics of the developed friction composites were analysed using the following tests. Density characterisation was done in a digital density apparatus that works on the Archimedes principle. Hardness was studied using the ' $\mathrm{K}$ ' scale having a steel ball indenter of $3.125 \mathrm{~mm}$ diameter and a load of $1500 \mathrm{~N}$ was applied. The acetone extraction test was used to find the uncured resins in developed pads. The test was conducted on the Soxhlet extraction apparatus. To identify the loss of ignition (LOI), a silica crucible containing 5 to 10 grams of the developed samples was introduced into the muffle furnace. It was kept in the furnace at $800{ }^{\circ} \mathrm{C}$, for two hours [9]. After ignition, the difference in weight was calculated; reduced LOI is advisable for better thermal resistance. The above-stated tests were done based on IS2742 Part-3 of 1994 . The brake pads were heated up to $200^{\circ} \mathrm{C}$ and maintained at that temperature for 30 minutes to find the 'hot shear strength'. The 'cold shear strength' was done at normal room temperature. These tests were conducted based on ISO 6312 [5]. To characterise material porosity, a sample size of $25 \mathrm{~mm} \times 25 \mathrm{~mm}$ was placed in a desiccator for 24 hours, after which it was soaked in a pre-heated SAE 90 -grade oil bath at $90^{\circ} \mathrm{C}$ $\pm 1^{\circ} \mathrm{C}$ for 8 hours. After a simulated time, the heater was turned off and the sample cooled in ambient temperature. This test was following JIS D 4418.

\section{Fade and Recovery Characterisation based on IS2742 Part 4}

The Chase testing was done as per IS2742 Part-4 of 1994, with a specimen size of $25 \mathrm{~mm}$ $\times 25 \mathrm{~mm}$, sliding against a cast iron drum of $280 \mathrm{~mm}$ diameter. 320 grit size abrasive paper was used to polish the drum. To enable $95 \%$ contact of the specimen with the drum, burnish was accomplished with a load of $440 \mathrm{~N}$ for 20 minutes at a speed of $308 \mathrm{rpm}$. The test schedule consisted of baseline, two (fade and recovery cycles) and one wear cycle which were realised at $660 \mathrm{~N}$. Friction force readings were obtained and recorded with an interfaced computer. During the test, friction force readings were taken related to the brake applications. The thickness and weight of the composite for each sample was measured before and after the test using a digital micrometre and digital weighing balance possessing $0.001 \mathrm{~g}$ accuracy respectively. Thickness was measured at four different points, with an average considered. In the case of the weight measurement, the sample 
weight was measured thrice, and the average is presented in the results. The thickness loss $\%$ and weight loss $\%$ were reported in the results. Details of the experimental procedure of Chase friction test is given in Table 4.

Table 4. Experimental procedure for the Chase test based on IS 2742 Part-4 of 1994.

\begin{tabular}{|c|c|c|c|c|c|c|c|c|c|}
\hline \multirow[t]{2}{*}{ Stages } & \multirow{2}{*}{$\begin{array}{l}\text { Speed } \\
(\mathrm{rpm})\end{array}$} & \multicolumn{2}{|c|}{$\begin{array}{c}\text { Temperature } \\
\left({ }^{\circ} \mathrm{C}\right)\end{array}$} & \multirow{2}{*}{$\begin{array}{l}\text { Load } \\
(\mathrm{N})\end{array}$} & \multicolumn{2}{|c|}{ On time } & \multirow{2}{*}{$\begin{array}{c}\text { Off } \\
\text { time } \\
\text { sec }\end{array}$} & \multirow{2}{*}{$\begin{array}{c}\text { No. of } \\
\text { applicatio } \\
\text { ns }\end{array}$} & \multirow[t]{2}{*}{ Heater } \\
\hline & & Min & Max & & $\min$ & $\mathrm{sec}$ & & & \\
\hline Burnish & 308 & - & 93 & 440 & 20 & - & - & 1 & Off \\
\hline Baseline-I & 411 & 82 & 104 & 660 & - & 10 & - & 20 & Off \\
\hline Fade-I & 411 & 82 & 289 & 660 & 10 & - & - & 1 & On \\
\hline Recovery-I & 411 & 261 & 93 & 660 & - & 10 & - & 1 & Off \\
\hline Wear & 411 & 193 & 204 & 660 & - & 20 & 10 & 100 & Off \\
\hline Fade-II & 411 & 82 & 345 & 660 & 10 & - & - & 1 & On \\
\hline Recovery-II & 411 & 317 & 93 & 660 & - & 10 & - & 1 & Off \\
\hline Baseline-II & 411 & 82 & 104 & 660 & - & 10 & 20 & 20 & Off \\
\hline
\end{tabular}

Parameters like $\mu_{\text {normal }}, \mu_{\text {hot, }} \mu_{\text {performance, }} \mu_{\text {fade }}, \mu_{\text {recovery, fade }} \%$, recovery $\%$ and wear loss $\%$ (thickness and weight) were quantified as per the literature [17, 18]. For all the tests, calibrations of the testing equipment were insured as per National Traceability Standards by NABL certified laboratories, and 5\% error was acceptable as per industry practice. Worn surface characteristics of the Chase tested samples were analysed using a Tescan VEGA 3LMU SEM machine of the Czech Republic possessing tungsten heated cathode electron gun.

\section{Extension Evaluation Method}

Extensive Evaluation Method is used to rank the Chase tested friction composites. This is a decision-making tool which is helpful to arrive at a clear idea about the performance. This procedure uses weighed average-dependent degree, which is defined as the friction stability of the composites that can be used to compare the quality and to rank them accordingly [19]. It is assumed that there is an interval $X=\langle a, b\rangle$ and a point $M \in X$, the dependent function of any point $x \in(-\infty,+\infty)$, for the interval between $X$ and ' $M$ ' point is expressed as given below in Eq. (1).

$k(x)= \begin{cases}\left(\frac{x-a}{M-a}\right), & x \leq M \\ \left(\frac{b-x}{b-M}\right), & x \geq M\end{cases}$

Then, the basic dependent function $k(x)$ has the following properties:

$$
\begin{array}{cl}
\text { i. } & k(x) \text { reaches its maximum at point } x=M, \text { and } k(x)=1 \\
\text { ii. } & x \in X \text { and } x \neq a, b \leftrightarrow K(x)>0 \\
\text { iii. } & x \notin X \text { and } x \neq a, b \leftrightarrow K(x)<0 \\
\text { iv. } & x=a \text { or } b \leftrightarrow K(x)=0
\end{array}
$$

In Chase testing the coefficient of different cycles of Chase tests are ranked where, $\mathrm{x}$ is the coefficient of friction, the dependent function that reached its maximum at the 
middle point of the interval $\left(M=\left(\frac{a+b}{2}\right)\right)$. Then the dependent function is expressed using the following Eq. (2).

$k(x)= \begin{cases}\left(\frac{2(x-a)}{b-a}\right), & x \leq\left(\frac{a+b}{2}\right) \\ \left(\frac{2(b-x)}{b-a}\right), & x \geq\left(\frac{a+b}{2}\right)\end{cases}$

Upon substituting the coefficient values, the typical dependent function for fade I cycle is given in Eq. (3) as

Fade I cycle is $\mathrm{k}_{\mathrm{b} 1}(\mathrm{x})=\sum_{\mathrm{i}=1}^{12} \alpha_{\mathrm{i}} \mathrm{k}(\mathrm{x} \mathrm{i}) ; \alpha_{1}=\alpha_{2}=\ldots \ldots \ldots \alpha_{12} \quad=1 / 12$

Similarly, for all the other cycles, which result in coefficients of friction are solved by substituting in Eq. (2). The typical examples for calculation are given in results and discussion sections in Eq. (9) and (10).

To find the overall $k_{\mu}(x)$ for the coefficient of friction calculation, the Eq. (4) is used.

$k_{\mu}(x)=\left(\frac{k_{\mu 1}(x)+k_{\mu 2}(x)+k_{\mu 3}(x)+k_{\mu 4}(x)}{4}\right)$

Wear performance of the Chase tested composites are ranked as per the belowgiven procedure. Wear rate is measured as weight loss and thickness loss and the individual intervals are $\langle a, b\rangle$, where each value has the same weight. The dependent function is thus given by Eq. (5).

$k(x)=\left\{\begin{array}{lc}\left(\frac{x-a}{M-a}\right), & x \leq M \\ 1, & x=a \\ \left(\frac{b-x}{b-M}\right), & x \geq M\end{array}\right.$

Based on the test results value, by substituting Eq. (5), the dependent function is calculated for various wears. The typical equation for weight loss of the composite is shown in Eq. (6).

$\mathrm{k}_{\mathrm{wr} 1}(\mathrm{x})==\sum_{\mathrm{i}=1}^{4} \delta \mathrm{ik}(\mathrm{xi}) ; \delta_{1}=\delta_{2}=\delta_{3}=\delta_{4}$

The typical examples for the thickness loss are shown in Eq. (11) to (14). To find the overall wear dependent function $k_{w r}(x)$ for the tested composites, Eq. (7) is used.

$\mathrm{k}_{w r}(x)=\left(\frac{k_{w r 1}(x)+k_{w r}(x)+k_{w r 3}(x)+k_{w r 4}(x)+k_{w r 5}(x)+k_{w r 6}(x)}{6}\right)$

Based on the results of $k \mu(x) \& k_{w r}(x)$ (coefficient of friction and wear rate), the weighted average dependent degree $k_{\text {overall }}(x)$ is found. This describes the overall quality of the developed composite by using Eq. (8).

$k_{\text {overall }}(x)=k_{b}(x)+k_{w}(x)$

Finally based on the $k_{\text {overall }}(x)$, higher the better criterion is considered. 


\section{RESULTS AND DISCUSSION}

\section{Thermal Stability of Varying Ingredients and Composites}

TGA plays a crucial role in determining the thermal stability of the materials, as shown in Figure 3. Degradation of thermally processed CBS powder takes place in a single phase in a range of $600-750^{\circ} \mathrm{C}$. Weight loss at the end of $800^{\circ} \mathrm{C}$ is $43.01 \%$. The single stage degradation is mainly due to the absence of proteins, moisture, chitin etc. which were burnt during thermal processing. This agrees with the theoretical decomposition of calcium carbonate [14]. The decomposition reaction is given in Eq. (9).

$\mathrm{CaCO}_{3} \rightarrow \mathrm{CaO}+\mathrm{CO}_{2}$

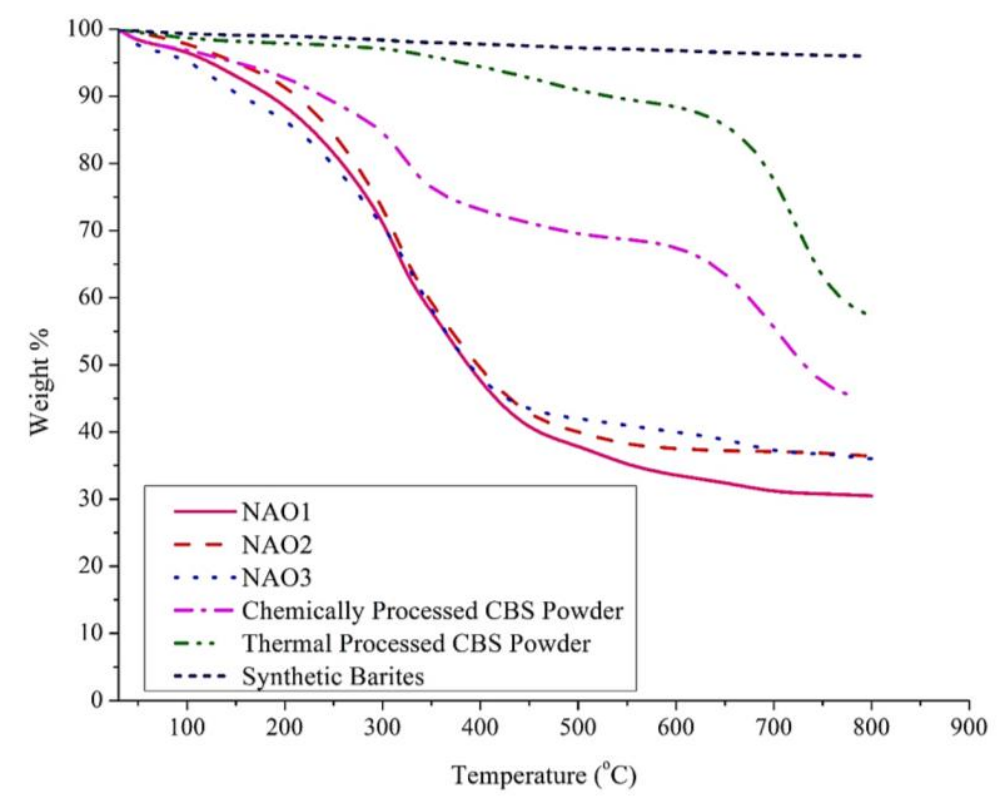

Figure 3. TGA of the varying ingredients and composites.

The improvement in thermal stability is mainly due to the high thermally stable ingredient $\mathrm{CaCO}_{3}$ in $\mathrm{CBS}$ powder. It constitutes about $70 \%$ of the total shell composition, which agrees with the literature [20]. Decomposition mainly occurs in three different stages in chemically processed CBS. In the first phase, at $100-250^{\circ} \mathrm{C}$, the degradation of protein traces and moisture from the crab shell surface occur, followed by the degradation of the saccharide structure of the molecule at $250-360^{\circ} \mathrm{C}[16,21]$. This includes the dehydration of saccharide rings, polymerisation and decomposition of the acetylated and deacetylated units of chitin biopolymeric fibres. This stage has more weight loss due to the different structures of $\alpha \& \beta$ chitin. At a range of $600-750^{\circ} \mathrm{C}$, the weight loss is mainly due to $\mathrm{CaCO}_{3}$, which is a major constituent and some other minerals present in the minimum percentage in the composition [16, 21].

Weight losses for the chemical treated CBS powder during the decomposition stages are as follows. During the first stage at $100-250^{\circ} \mathrm{C}$, which is around $9.2 \%$, followed by chitosan fibre by $15.2 \%$ and in the case of calcium carbonate it is $32.41 \%$, the rest are residue. In the case of synthetic barites, there is only one stage of degradation around 490$630^{\circ} \mathrm{C}$, which was due to the liberation of sulphur dioxide while the barium oxide remains asa residue. In the developed samples, a similar trend is seen as the initial decomposition 
shifts its value upon addition of thermally processed CBS powder in NAO2, this confirms the thermally stable powder in the matrix [22]. Similarly, in the case of NAO3 where the degradation changes as there is an increase in the temperature. The decomposition of the developed composites follows three stages due to the cocktail of ingredients present in it. Degradation takes place in the following sequence, namely phenolic resin (binders), followed by aramid and other partially thermally stable materials and finally by the varying ingredients and other stable ingredients. The residue is due to highly stable elements like alumina, steel fibre, residues of varying ingredients etc. The NAO2 showed higher thermal stability compared to NAO1, NAO3. It is a well-known fact that the higher the presence of the thermally stable materials in the composition, the higher its thermal stability. A similar trend is seen in NAO2, NAO3. Weight loss $\%$ at $800^{\circ} \mathrm{C}$ for NAO1, $\mathrm{NAO} 2$ and NAO3 are about $68 \%, 63 \%, 63.5 \%$ and respectively. The weight loss of $\mathrm{NAO} 2$ is 1.1 times lower than NAO1 and 1 time lower than NAO3. There also exist some undulations in the curve, due to the mixing of various ingredients that came into existence during testing of the cured composite powder.

\section{Characteristics of Composites}

The test results of various characterisations are given in Table 5 where samples were tested thrice for the reliability of the results, and the consistent average values are given. The density of the NAO3 is higher due to the presence of finer synthetic barites also and due to its higher density $\left(4100 \mathrm{~kg} / \mathrm{m}^{3}\right)$ which fills the space. Similarly, the hardness was higher NAO3 due to filling gaps by barites in the brake pads. There is a correlation between hardness, density and porosity. The higher the density, the higher the hardness, and the lower the porosity [23]. A similar trend is seen in the present study, where the NAO1 showed better porosity compared to others due to its coarse nature which produced space between ingredients in the matrix (not voids) leading to reduced hardness and density. Even the density of chemically treated CBS powder is less than others, as seen in Table 1. Acetone extraction of NAO3 is more followed by NAO2 due to the presence of a higher content of uncured resin caused due to lack of heat penetration in the composite. The fine synthetic barites and thermally processed CBS powder fill the pores thereby preventing heat penetration, i.e., compact nature.

In many cases, high dense composites showed similar trends [18]. But this concept showed an inverse trend in the case of the special graphite based NAO friction material, the increase in density reduced acetone extraction due to the presence of the thermally conductive graphite present in the formulation which made the composite conduct heat and is cured [17]. The current study is mineral filler's, thermal conductivity (TC) will be lower, and the TC study is out of the scope of the current study. Shear strength is mainly dependent on the bonding of backplate and friction materials, which is possible due to matrix adhesion and better curing. The fine thermal processed powder fills the adhesion pores reducing bonding strength value.

Similarly in the case of NAO3, which was due to the filling of fine synthetic barites leading to such behaviour. This can even be found from the acetone extraction; where less extract value leads to better the curing substantially resulting in higher strength. Whereas, in literature, it was reported that the strength increases with the use of fine powders in the composite [24]. This is cross breaking strength, not the shear strength, which is the adhesion between backplate and friction material. 
Table 5. Various characteristics measured for the developed composites.

\begin{tabular}{lcccccc}
\hline S.No. & Properties & Unit & $\begin{array}{c}\text { Test } \\
\text { standards }\end{array}$ & NAO1 & NAO2 & NAO3 \\
\hline 1 & Density & $\mathrm{kg} / \mathrm{m}^{3}$ & & 2300 & 2450 & 2570 \\
2 & Hardness & HRS & IS 2742 & 106 & 122 & 130 \\
3 & Acetone & & Part-3 & 1.59 & 1.75 & 1.85 \\
4 & extraction & $\%$ & & 21 & 18 & 25 \\
5 & Loss of ignition & & & $46 \times 10^{4}$ & $40 \times 10^{4}$ & $36 \times 10^{4}$ \\
& Cold shear & & & $30 \times 10^{4}$, & $26 \times 10^{4}$, & $23 \times 10^{4}$, \\
6 & strength & $\mathrm{kg} / \mathrm{m}^{2}$ & ISO 6312 & & $27 \times 10^{4}$ & $24 \times 10^{4}$ \\
7 & Hot shear strength & & & $31 \times 10^{4}$ & 27.1 \\
\hline
\end{tabular}

\section{Tribological Characteristics based on Chase Test}

\section{Fade and recovery characteristics}

The Chase test was performed as per the IS2742 Part-4 standards to study the friction and the wear properties considering temperature. The resultant graph from the tribological tests is shown in Figure 4. The thermally processed CBS powder based composite NAO2 and NAO3 showed a higher coefficient of friction at the initial stage. This is in accordance with literature findings of Matejka et al. [25] for jute and powderised hazel nutshell fillers for non-metallic friction composites. Another important concept for the high friction coefficient of NAO2 during baseline, fade cycles was mainly due to the abrasive action of the fillers obtained from the surface of the composites. The worn out fillers come contact between the drum and the friction material interface by forming third body particles leading to an increase of value. This was similar to the third body abrasive wear phenomenon [26]. The similar behaviour could have been taken place in the NAO3. Another reason is the chitin present in the structure of the crab shell, which is removed, Calcium carbonate is present as small amorphous crystallites and calcite, which boost friction. It is also proved that the higher hardness of the composite increased the friction value, which was in accordance with the literature findings of Cho et al. [27] and Kus \& Altiparmak [28].

Some researchers reported that mechanical properties do not have a direct correlation with frictional behaviour [24]. But the current postulate shows in accordance with friction behaviour alone. The increase in temperature results in a reduction in the coefficient of friction termed as thermal fade. Thermal fade plays a crucial role in determining friction performance characteristics during braking. The low fade rate is always advisable for better performance, which is in accordance with the findings of Aranganathan et al. [29]. The hot friction coefficient is lower than the normal friction coefficient. A similar trend was also noticed in the current study, but in the case of fly ash based bronze, brake lining showed an inverse trend was seen due to the formation of nucleated plateaus [28] made up of abrasive fly ash. The $\mu_{\text {normal, }} \mu_{\text {hot }}$ of NAO1 (0.385, $0.371)$, NAO2 $(0.391,0.367)$, NAO3 $(0.365,0.343)$ respectively are shown in Figure 5(a). 

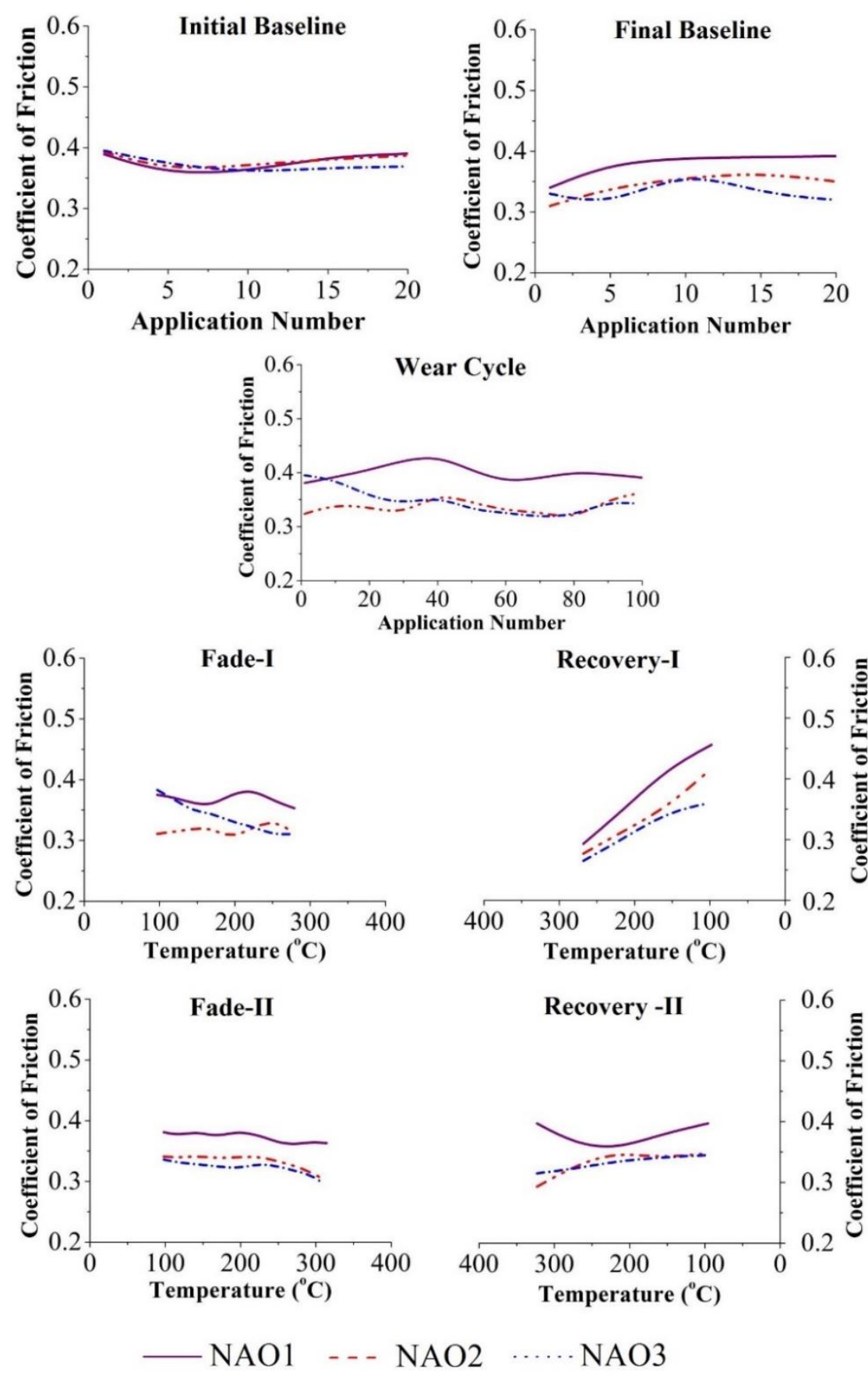

Figure 4. Resultant Chase test graphs of the developed composites.

These values are in accordance with the automobile brake industrial values $(0.3$ to 0.5 ) [30]. Friction is higher in case of the $\mu_{\text {normal }}$ for NAO2 while in $\mu_{\text {hot }}$ it is less; due to its recovery behaviour. In the case of $\mu_{\text {normal }}$ the values are calculated as per the fade cycle; a higher coefficient of friction in fade cycle-II increases that value. In $\mu_{\text {hot }}$ friction, value is dependent on the two recovery cycles and one fade cycle as per the equations are given in the literature $[17,18]$. Hence, the value is less, due to the high recovery rate for NAO1 as explained in the forthcoming sections. The main reason for increased fade rate in the case of NAO2 and NAO3 are due to the excessive friction caused by the degradation of polymer ingredients which debond the fillers from it, leading to more abrasive action enhancing the friction. At the end of the second fade there is an increase 
in friction for the NAO1 due to the stability of the composites, i.e. less worn out and low debonding from resin which could transfer the heat effectively due to its porosity. The resultant graph in Figure 4 shows more fluctuations for both the composites. But in $\mathrm{NAO} 2$, it is very high (second fade and wear) mainly due to the thermally processed CBS powder that has high thermal stability as seen in Figure 3. This comes into friction interface, and the resin materials cause the stick-slip with the interface that changes drastically, as in accordance with the literature [31]. It was reported in the literature that these fluctuations are due to the non-homogenous heat load on the contact surface of the friction composite. The reduction in friction coefficient for fade cycles compared to recovery cycles are because of the thermal softening of resin. This reduces the hardness of the composites upon braking and $\mathrm{CO}_{2}$ gases are released as a result of thermal degradation or pyrolysis. These gases entrapped between the sliding interfaces, exert an opposing force to the applied load thereby reducing friction [28, 32]. Fade rate for the developed composites NAO1, NAO2 and NAO3 are $1.71 \%, 2.05 \%$ and $16.3 \%$ respectively. It is in literature states that lower the fade rate the better the performance [29]. The process of regaining its friction coefficient value upon cooling is termed as recovery. The higher recovery rate is the key deciding criteria for ideal brake material.

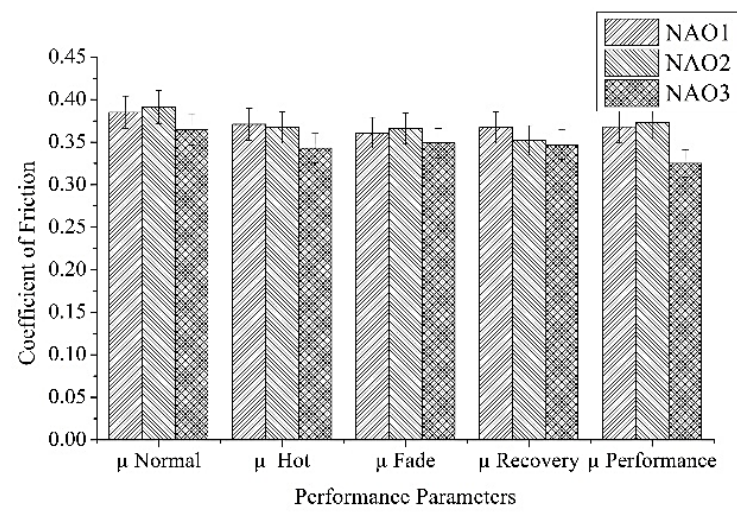

(a)

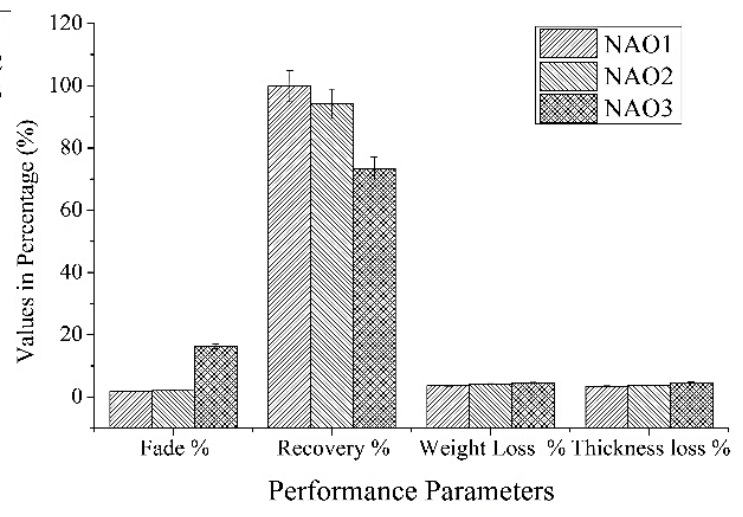

(b)

Figure 5. (a) Normal, hot, performance, fade and recovery coefficient of friction, and; (b) fade rate, recovery rate, weight loss, thickness loss (all in percentage) of composites.

In the present study, the recovery rate is higher for NAO1 compared to NAO2 and NAO3. The enhanced results are mainly due to the porosity of the tested composites, where porosity of NAO1 is 1.75 times higher than that of NAO2 and 1.97 times higher than that of NAO3. This is due to the coarse structure of chemically treated CBS powder, which allows more heat to dissipate to the surroundings leading to effective results. Another possible reason for such behaviour is that during recovery, the blower is kept on, for fade NAO2 which reveals high friction due to the third body worn particles of thermally processed CBS powder at the interface. But when the blower is on, polymeric materials are transferred back while these fillers are wiped away by the blowing air. This is also one of the main causes for reduced friction in recovery for NAO2. The recovery rate of NAO1 $(99.86 \%)$ is 1.05 times higher than NAO2 $(94.24 \%)$, while it 1.36 times higher than NAO3 (73.4\%). The values are presented in Figure 5(b). Higher the recovery, the better the thermal performance; these results are in good agreement with the findings of Thiyagarajan et al. [5]. Performance coefficient of friction is calculated based on the average of friction coefficient from the fade and recovery cycles after $100^{\circ} \mathrm{C}$, in where 
NAO2 had 0.373 while NAO1 showed 0.368 . This is mainly due to the high friction coefficient during the fade cycles in case of NAO2. NAO3 composites showed more abrupt changes in friction levels, i.e. it increased at the start, but it reduced upon further cycles. This is mainly due to its lesser porosity and debonding nature. It is worth noting that the barites though thermally stable get entrapped between the interface causing more undulations in the friction level leading to worse fade and recovery results.

\section{Wear of the friction composites}

NAO2 showed higher wear due to the wearing out of the samples by an interface temperature rise. A similar trend was noticed in the case of flax fibres reinforced friction composites, where there was no fade phenomenon up to $300^{\circ} \mathrm{C}$ but a higher wear rate. This shows that higher coefficient and lower wear rate is not possible simultaneously in many cases, and the current study proves the same [31,33]. It is also stated that hardness of the brake friction materials does not always reduce the wear rate. Similarly, NAO2, NAO3, which has higher hardness, showed poor wear resistance, which is in accordance with the findings of literature $[34,35]$. The wear rate of NAO1 is less compared to NAO2 mainly due to the following reasons. The presence of protein inside the crab shell in the case of chemically treated CBS powder liberates carbon atoms upon application of braking at the interface, which acts as lubricant thereby reducing the wear rate by forming a friction film. A similar trend was seen in coconut char based friction composites where the liberated carbon acts as a lubricant. It was also reported that the lubricant so formed would replace the role of graphite in the composite [11]. Zhou et al. [36]confirmed that if the water and protein are removed from the crab shell, then it leads to poor results. A similar trend is seen in NAO2 composites filled with thermal processed CBS powder. The weight loss and thickness loss $\%$ for NAO1, NAO2 and NAO3 samples are $3.6 \%$, $4.1 \%, 4.5 \%$ and 3.4\%, 3.7\%, 4.6\% respectively as shown in Figure 5(b). These values are in trend with the findings of Maleque and Atiqah [37] where optimal natural materials in composition showed better results than the higher ones.

\section{Worn Surface Characterisation}

Scanning Electron Microscopy paved the way for studying the varied behaviour of the worn surface of the Chase tested composites. Figure 6 (a) shows the primary plateau and secondary plateaus formation of the chemically treated CBS powder based NAO1 composite. The primary plateaus are termed as load-bearing capacity elements of the friction composites due to the exposure of fibres and other strength ingredients on braking. Secondary plateaus are shining patches produced upon the back transfer and re back transfer of polymeric and low stable ingredients by braking. These destroy the friction characteristics and produce more weight loss for the composite [38,39]. Figure 6(a) shows more primary plateaus than Figure 6(b), which represents the plateaus of the thermally processed CBS powder based NAO2 composites which have more secondary plateaus. Figure 6(c) shows plateaus formation where some are nucleated due to their low thermal withstanding ability. The scars are due to the ploughing action of the hard ingredients of the NAO1 composites. In Figure 6(d) there is more nucleation of plateaus for NAO2 compared to NAO1, due to the excess heat generated, causing the degradation of polymeric ingredients. This disintegrates the thermal processed CBS filler from the composite, leading to the abrasive nature of the interface and preventing the formation of large size plateaus. Figure 6(e) represents the crack and pit formation in the NAO1 
composite, generated by the heat produced at the interface. Figure 6(f) represents the crack and pits in NAO2. The cracks are more because the heat generated at the interface is not carried away in NAO2 due to its dense (less porosity) structure leading to the deterioration of the composite performance.

Figure 7(a) shows the removal of coarse chemical treated CBS powder from the surface of tested NAO1 composites; it also shows some wear debris which is attached to the surface. Figure 7(b) shows debonding of ingredients from the surface and wear debris due to the back transfer in the NAO2 composite. This shows more delamination wear mechanism prevailing on the surface of the composite. In Figure 7(c) the surface cracks are generated due to the interface effect between the drum and the composite (particle debonding). The composite had good porosity which helps to remove the interface heat caused in NAO1, while Figure 7(d) shows more deep cracks compared to the Figure 7(c), this was mainly due to the poor heat removal nature of the composite NAO2. Thus, from the SEM images, it is clear that NAO1 showed enhanced behaviour during tribological testing than the NAO2 composite.

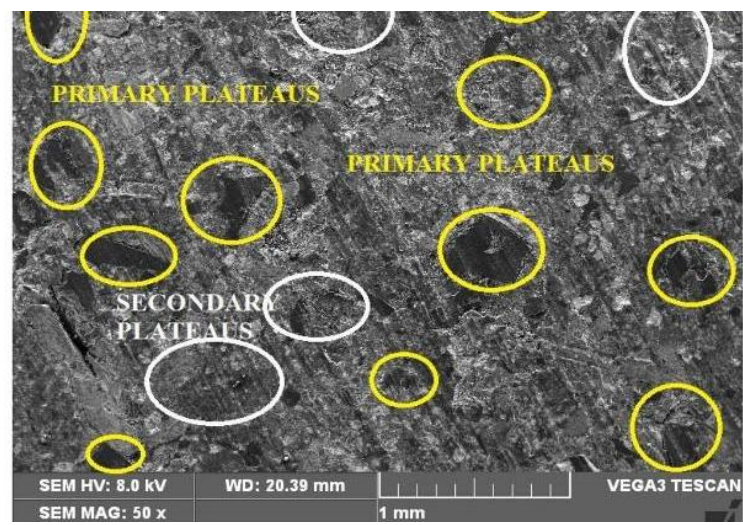

(a) more primary and less secondary plateaus in NAO1

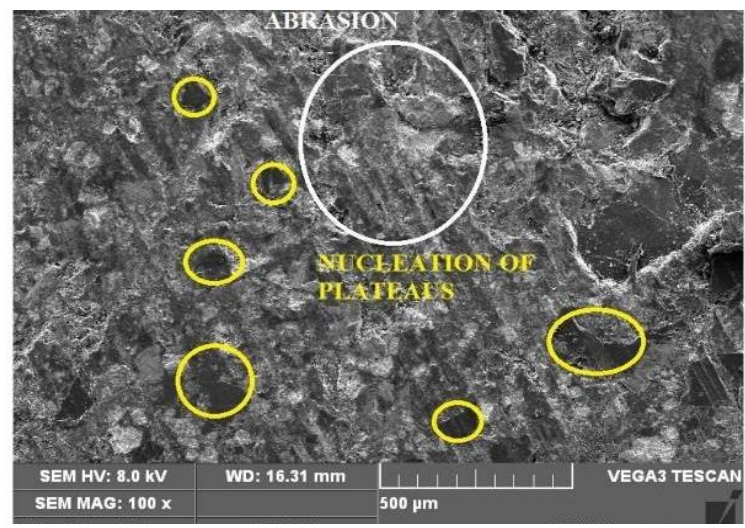

(c) nucleation of plateaus and scars caused due to abrasion in NAO1

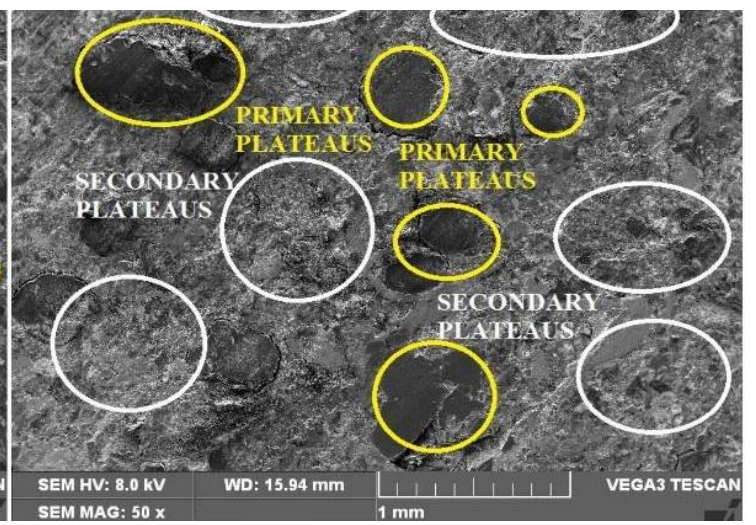

(b) less primary and more secondary plateaus in $\mathrm{NAO} 2$

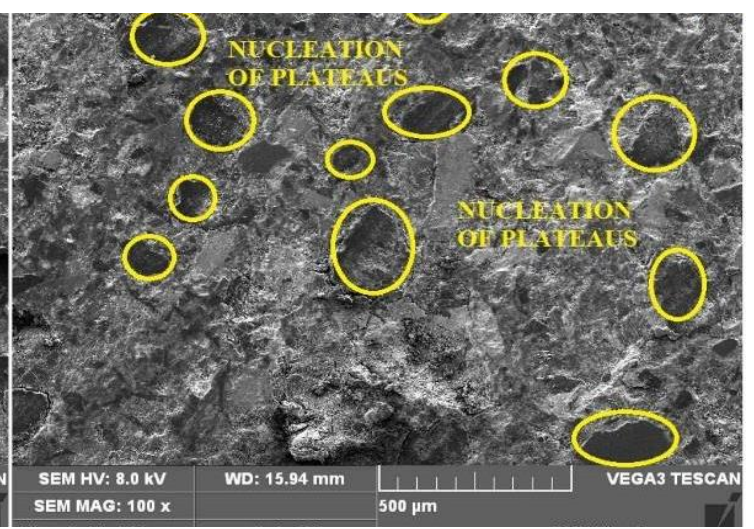

(d) more nucleation of plateaus in NAO2 


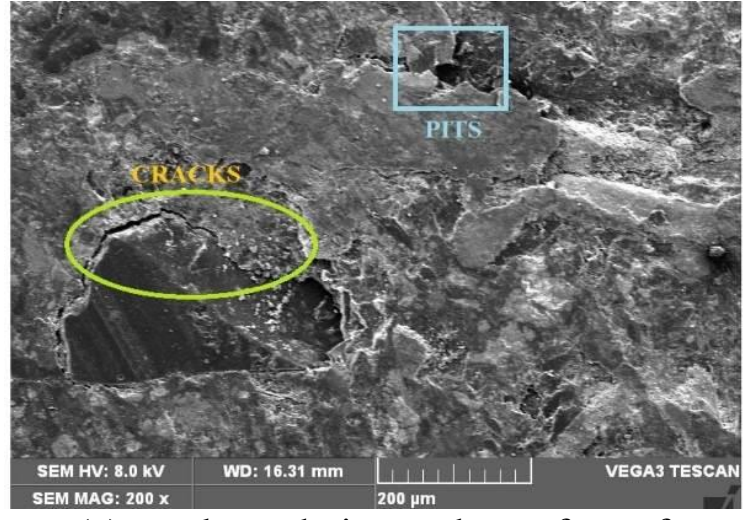

(e) cracks and pits on the surface of $\mathrm{NAO} 1$

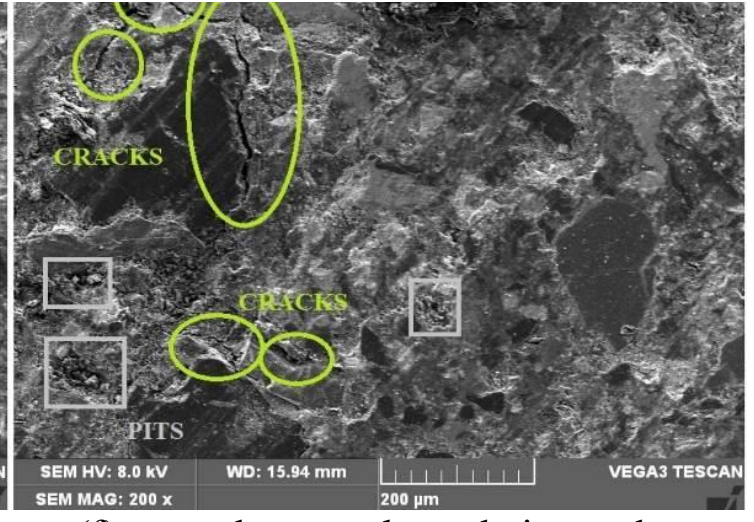

(f) more deep cracks and pits on the surface of NAO2

Figure 6. SEM observation showing composites.

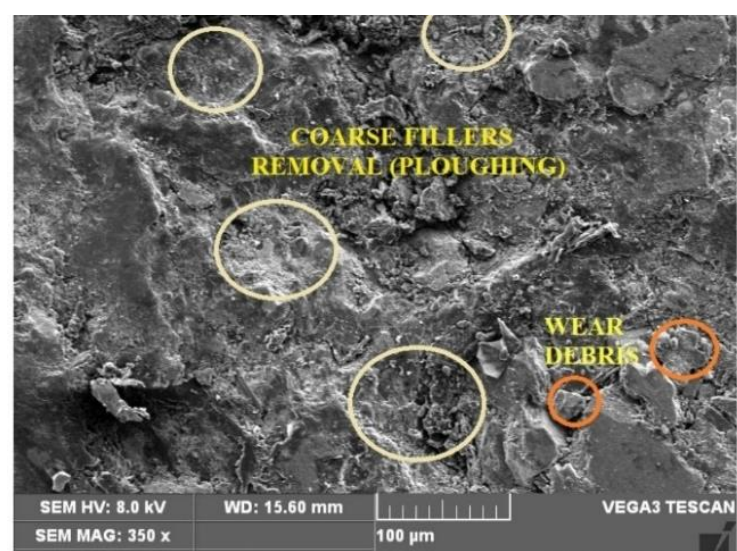

(a) fillers removal and wear debris in NAO1

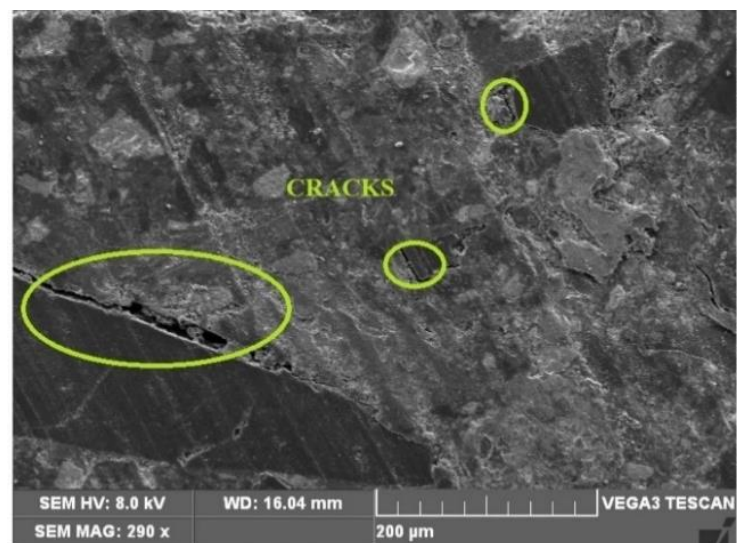

(c) fragmentation of surfaces due to particle debonding in NAO1

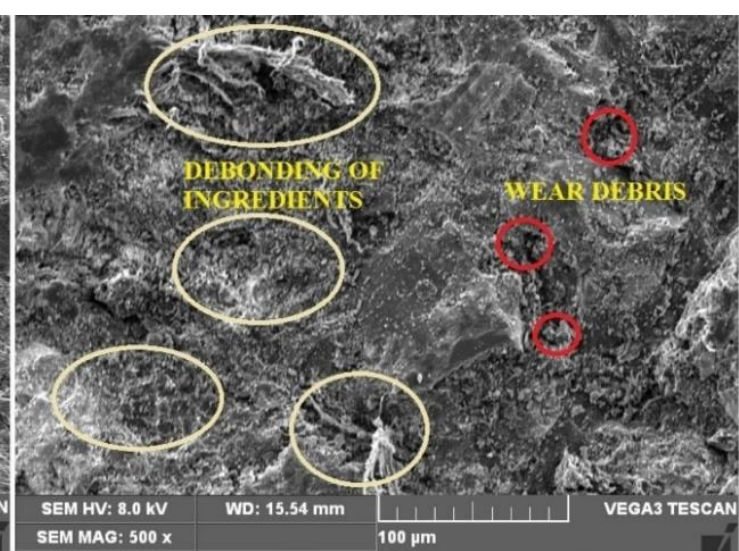

(b) debonding of ingredients in large number and wear debris in $\mathrm{NAO} 2$

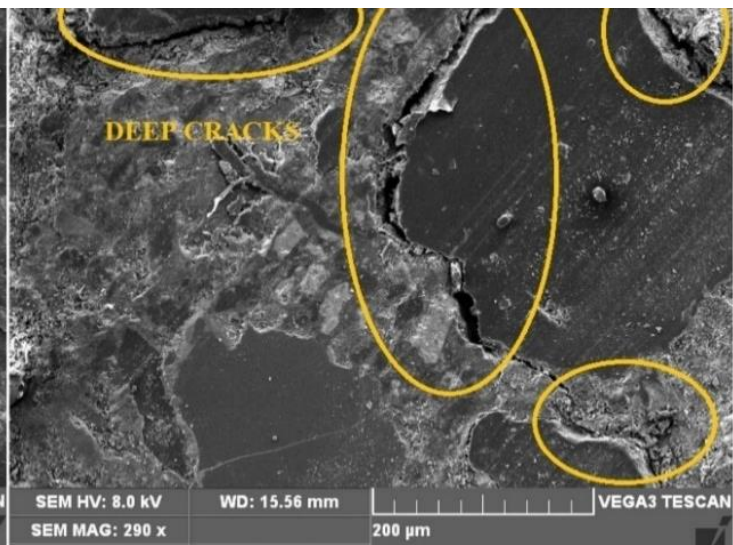

(d) more deep cracks in more number on the surface of NAO2

Figure 7. SEM observations showing NAO1 and NAO2 composite.

In Figure 8(a) there are more secondary plateaus in NAO3 with less primary plateaus compared to NAO2, NAO1 due to more back transfer caused by polymeric materials. Due to its poor heat dissipation nature (less porosity) more surface cracks are 
seen. It could also be seen that there is more wear debris that got spread over the surface causing more undulations in the friction level as stated in the previous sections. Thus NAO3 reveals poor characteristics like more debonding of plateaus, debonding of materials and cracks as shown in Figures 8(a) and 8(b).

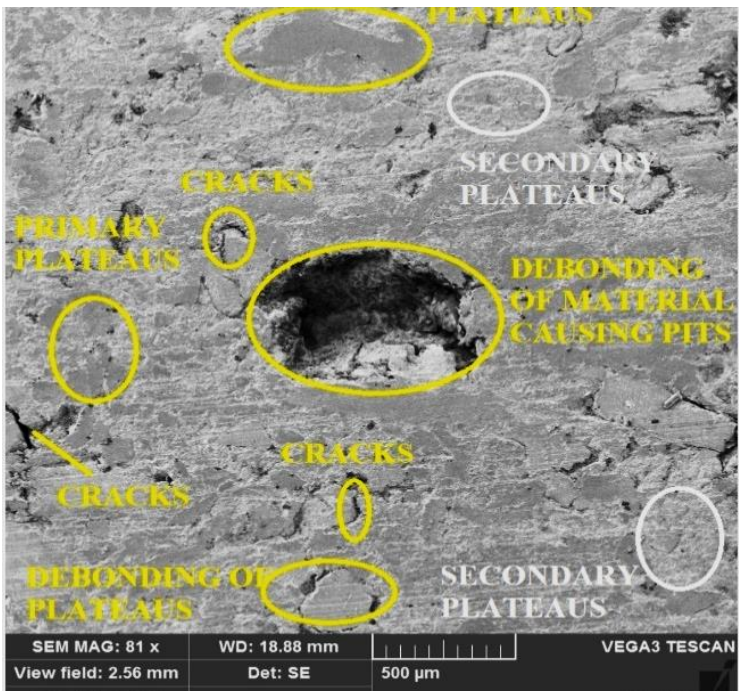

(a)

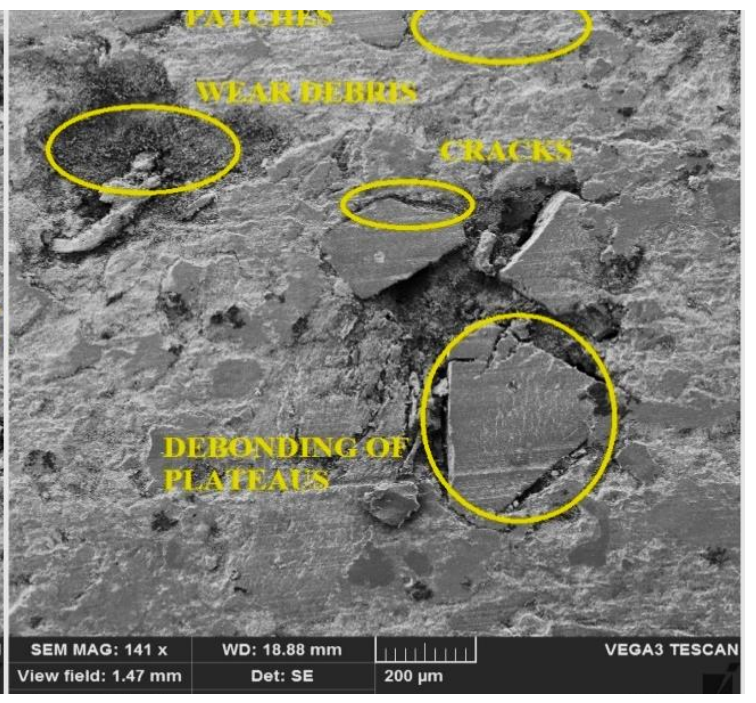

(b)

Figure 8. SEM image of NAO3 showing (a) primary, secondary plateaus with debonding of materials and cracks and; (b) closure view of the worn surface showing debonding of plateaus, wear debris, back transfer plateaus, deep cracks.

\section{CONCLUSION}

In this study, eco-friendly friction materials were developed by varying chemically treated and thermally processed crab shell powders as fillers in comparison within CBS powder free sample. The developed composites were tested for its physical, chemical, thermal, mechanical characteristics as per Industrial standards. The fade and recovery behaviour was studied using the Chase test and the following conclusions were drawn.

i. The removal of fat, protein, and other organic constituents from the CBS was effectively done by the thermal processing. It drastically reduced the time from 24 hours in the case of chemical treated one to 15 minutes as well as the cost involved in the production.

ii. Thermally processed CBS powder and its friction composite showed better thermal stability compared to others. It also showed high hardness, density and loss on ignition characteristics.

iii. The performance, normal and fade friction coefficient was higher for thermally processed CBS powder-based friction composites due to its abrasive nature and stable thermal nature.

iv. The hot and recovery friction coefficient was higher for chemically treated CBS powder-based composites due to it being coarse and another constituent behaviour.

v. Fade rate percentage was lower while the recovery rate percentage was higher for chemically treated CBS powder-based friction composites.

vi. Wear resistance was high for chemically treated CBS powder-based friction composites than for the others. 
vii. SEM observations of the Chase tested chemically treated CBS powder-based friction composites showed more primary had fewer secondary plateaus thereby forming fewer cracks and pits compared to thermally processed CBS powder based and CBS powder free friction composites.

viii. Based on the aspects of performance friction coefficient, thermally stability of the thermal processed CBS powder based NAO2 composite is better, while in the case of fade, recovery rate and wear loss chemically treated CBS powder based NAO1 composite is better.

ix. Overall CBS powder free friction composite showed poor tribological performance due to the poor dissipation and resistance characteristics, though it had thermal stability almost equal to thermally CBS based friction composite.

$\mathrm{x}$. Extensive Evaluation Method was very helpful in ranking the composites where the NAO1 composite ranked higher.

xi. Thus, Crab shell powder can be effectively used as a filler ingredient in the friction materials formulations in the context of the current global scenario.

\section{REFERENCES}

[1] Chan D, Stachowiak GW. Review of automotive brake friction materials. Proceedings of the Institution of Mechanical Engineers, Part D: Journal of Automobile Engineering 2004;218(9):953-66.

[2] Aranganathan N, Mahale V, Bijwe J. Effects of aramid fiber concentration on the friction and wear characteristics of non-asbestos organic friction composites using standardized braking tests. Wear 2016;354:69-77.

[3] Vijay R, Lenin Singaravelu D, Filip P. Influence of molybdenum disulfide particle size on friction and wear characteristics of non-asbestos based copper-free brake friction composites. Surface Review and Letters 2019:1-20.

[4] Shin MW, Kim YH, Jang H. Effect of the Abrasive Size on the Friction Effectiveness and Instability of Brake Friction Materials: A Case Study with Zircon. Tribology Letters 2014; 55: 371-379.

[5] Thiyagarajan V, Kalaichelvan K, Vijay R, Lenin Singaravelu D. Influence of thermal conductivity and thermal stability on the fade and recovery characteristics of non-asbestos semi-metallic disc brake pad. Journal of the Brazilian Society of Mechanical Sciences and Engineering 2016; 38: 1207-1219.

[6] Subramanian V. Friction Material for Brakes-A Copper and Titanate Free Nonasbestos Friction Material. Patent Application No 20100084232A1, USA, 2008.

[7] Aranganathan N, Bijwe J. Development of copper-free eco-friendly brake-friction material using novel ingredients. Wear 2016; 352-353: 79-91.

[8] Yawas DS, Aku SY, Amaren SG. Morphology and properties of periwinkle shell asbestos-free brake pad. Journal of King Saud University-Engineering Sciences 2016; 28: 103-109.

[9] Aigbodion VS, Akadike U, Hassan SB, et al. Development of asbestos-free brake pad using bagasse. Tribology in Industry 2010; 32: 12-17.

[10] Ibhadode AO, Dagwa IM. Development of asbestos-free friction lining material from palm kernel shell. Journal of the Brazilian Society of Mechanical Sciences and Engineering $2008 ; 30(2): 166-73$.

[11] Sutikno M, Marwoto P, Rustad S. The mechanical properties of carbonized coconut char powder-based friction materials. Carbon 2010; 48: 3616-3620. 
[12] Idris UD, Aigbodion VS, Abubakar IJ, et al. Eco-friendly asbestos free brake-pad: Using banana peels. Journal of King Saud University-Engineering Sciences 2015; 27: 185-192.

[13] Akıncioğlu G, Öktem H, Uygur I, et al. Determination of Friction-Wear Performance and Properties of Eco-Friendly Brake Pads Reinforced with Hazelnut Shell and Boron Dusts. Arabian Journal for Science and Engineering 2018; 43(9): 4727-4737.

[14] Ramdani N, Wang J, He XY, et al. Effect of crab shell particles on the thermomechanical and thermal properties of polybenzoxazine matrix. Materials \& Design 2014;61:1-7.

[15] Lenin Singaravelu D, Vijay R, Rahul M. Influence of Crab Shell on Tribological Characterization of Eco-Friendly Products Based Non Asbestos Brake Friction Materials. SAE Technical paper 2015-01-2676, 2015.

[16] Basosidik S, Pankaew P, Hoonnivathana E, et al. Characterization of Chitin Extracted from Waste Sources via XRD, FTIR, and TGA Techniques. Advanced Materials Research 2012; 488:1404-1408.

[17] Aranganathan N, Bijwe J. Special grade of graphite in NAO friction materials for possible replacement of copper. Wear 2015; 330-331: 515-523.

[18] Manoharan S, Vijay R, Singaravelu DL, et al. Experimental Investigation on the Tribo-Thermal Properties of Brake Friction Materials Containing Various Forms of Graphite: A Comparative Study. Arabian Journal for Science and Engineering 2019; 44: 1459-1473.

[19] Qi S, Fu Z, Yun R, Jiang S, et al. Effects of walnut shells on friction and wear performance of eco-friendly brake friction composites. Proceedings of the Institution of Mechanical Engineers, Part J: Journal of Engineering Tribology 2014;228(5):511-20.

[20] Ma X, Zhou B, Deng Y, et al. Study on CaCO3/PMMA nanocomposite microspheres by soapless emulsion polymerization. Colloids and Surfaces A: Physicochemical and Engineering Aspects 2008;312(2-3):190-4.

[21] Paulino AT, Simionato JI, Garcia JC, et al. Characterization of chitosan and chitin produced from silkworm crysalides. Carbohydrate Polymers 2006;64(1):98-103.

[22] Yao Z, Xia M, Ge L, et al. Mechanical and thermal properties of polypropylene (PP) composites filled with $\mathrm{CaCO} 3$ and shell waste derived bio-fillers. Fibers and Polymers 2014;15(6):1278-87.

[23] Talib RJ, Muchtar A, Azhari CH. Microstructural characteristics on the surface and subsurface of semimetallic automotive friction materials during braking process. Journal of Materials Processing Technology 2003; 140: 694-699.

[24] Bijwe J, Kumar M. Optimization of steel wool contents in non-asbestos organic (NAO) friction composites for best combination of thermal conductivity and tribo-performance. Wear 2007; 263: 1243-1248.

[25] Matějka V, Fu Z, Kukutschova J, et al. Jute fibers and powderized hazelnut shells as natural fillers in non-asbestos organic non-metallic friction composites. Materials \& Design 2013;51:847-53.

[26] Surojo E, Malau V, Ilman M. Effects of phenolic resin and fly ash on coefficient of friction of brake shoe composite. ARPN Journal of Engineering and Applied Sciences 2014;9(11):2234-40.

[27] Cho MH, Kim SJ, Kim D, et al. Effects of ingredients on tribological characteristics of a brake lining: an experimental case study. Wear 2005 258(1112):1682-7. 
[28] Kus $\mathrm{H}$ and Altiparmak D. Effects of fly ash content on the friction-wear performance of bronze-based brake lining materials produced by the hot-pressing method. Industrial Lubrication and Tribology 2015; 67: 612-621.

[29] Aranganathan N, Bijwe J, Khatri DS. Role of combination of hexagonal boron nitride and graphite in NAO friction material. Proceedings of the Institution of Mechanical Engineers, Part J: Journal of Engineering Tribology 2016; 230: 11071112.

[30] Mohanty S, Chugh YP. Development of fly ash-based automotive brake lining. Tribology International 2007; 40: 1217-1224.

[31] Boz M, Kurt A. The effect of Al2O3 on the friction performance of automotive brake friction materials. Tribology International 2007; 40: 1161-1169.

[32] Fono-Tamo RS, Koya OA. Influence of Palm Kernel Shell Particle Size on Fade and Recovery Behaviour of Non-asbestos Organic Friction Material. Procedia Manufacturing 2017; 7: 440-451.

[33] Gurunath PV, Bijwe J. Friction and wear studies on brake-pad materials based on newly developed resin. Wear 2007;263(7-12):1212-9.

[34] Ria Jaafar T, Ismail NI, Ismail MF, et al. Influence of steel fibres on friction behaviours with respect to speed, pressure and temperature. Industrial Lubrication and Tribology 2017;69(3):420-4.

[35] Öztürk B, Öztürk S. Effects of resin type and fiber length on the mechanical and tribological properties of brake friction materials. Tribology Letters 2011; 42: 339-350.

[36] Zhou F, Wu Z, Wang M, et al. Structure and mechanical properties of pincers of lobster (Procambarus clarkii) and crab (Eriocheir Sinensis). Journal of the mechanical behavior of biomedical materials 2010;3(6):454-63.

[37] Maleque MA, Atiqah A. Development and characterization of coir fibre reinforced composite brake friction materials. Arabian Journal for Science and Engineering 2013;38(11):3191-9.

[38] Manoharan S, Vijay R, Lenin Singaravelu D, et al. Investigation on tribological and corrosion characteristics of oxide-coated steel and mild steel fiber-based brake friction composites. Industrial Lubrication and Tribology 2019:71(3): 341347.

[39] Bijwe J, Kumar M, Gurunath PV, et al.. Optimization of brass contents for best combination of tribo-performance and thermal conductivity of non-asbestos organic (NAO) friction composites. Wear 2008;265(5-6):699-712.

[40] Vijay R, Lenin Singaravelu D, Jayaganthan R. Development and characterization of stainless steel fiber based copper-free brake liner formulation- A positive solution for steel fiber replacement. Friction 2019: 1-25.

[41] Lenin Singaravelu D, Vijay R, Filip P. Influence of various cashew friction dusts on the fade and recovery characteristics of non-asbestos copper-free brake friction composites. Wear 2019; 426-427(B):1129-1141. 


\section{APPENDIX}

\section{Extension Evaluation Method}

The results obtained after substituting the obtained test results for various parameters in Eq. (2) is shown in Figure 9. The dependent degree function for the fade 1 for NAO1 was calculated. The coefficient of friction for the fade-I cycles ( $\mathrm{x}_{1}$ to $\left.\mathrm{x}_{9}\right)$ are $0.375,0.371$, $0.362,0.357,0.376,0.384,0.365,0.353,0.342$.

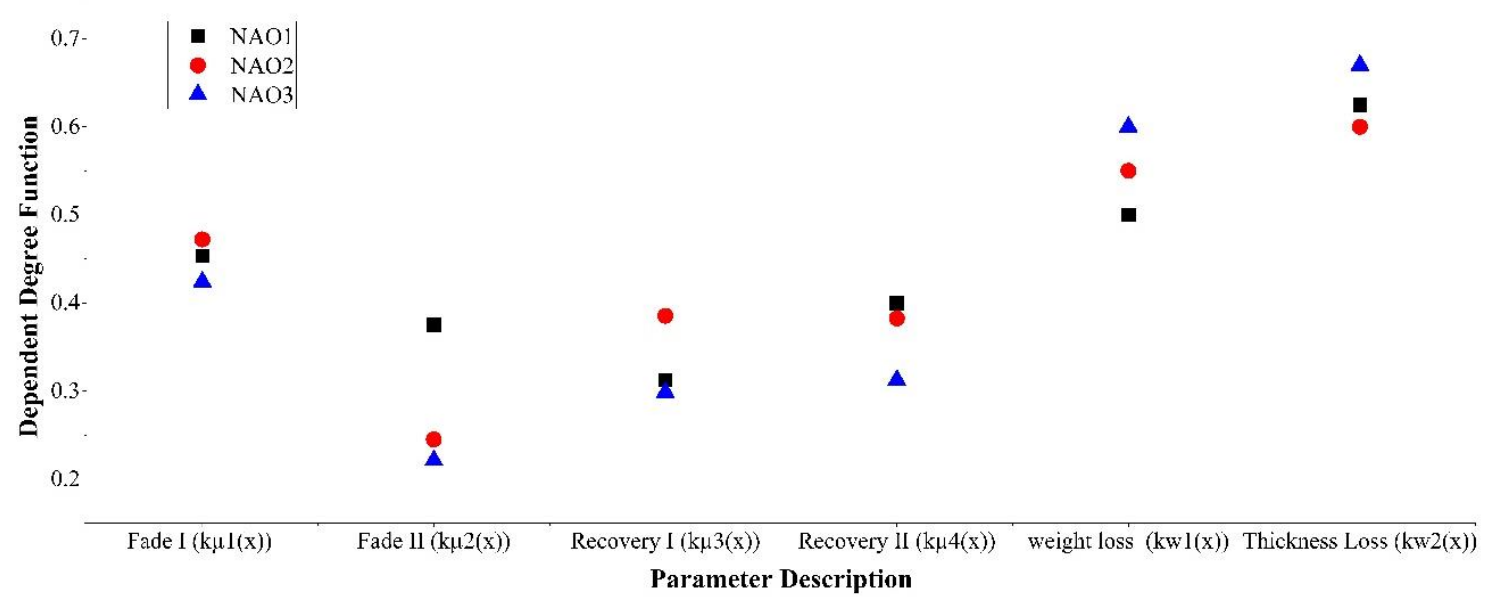

Figure 9. Parameter description vs dependent degree function for the Chase tested composites.

Using Eq. (2), $a=$ minimum $\mu$ in the range; while $b=$ maximum $\mu$ in the range. Then $\mathrm{x}$ refers to the coefficient of friction in that range.

$\mathrm{k}(\mathrm{xi})= \begin{cases}\left(\frac{2(\mathrm{xi}-0.342)}{0.384-0.342}\right), & \mathrm{xi} \leq\left(\frac{0.384+0.342}{2}\right) \\ \left(\frac{2(0.384-\mathrm{xi})}{0.384-0.342}\right), & \mathrm{xi} \geq\left(\frac{0.384+0.342}{2}\right)\end{cases}$

For example, $\mathrm{xi}=0.376$, which is $\mathrm{x}_{5}$, then it is greater than $\left(\frac{0.384+0.342}{2}\right)=0.363$ hence by Eq. (9),

$K\left(x_{5}\right)=\left(\frac{2(0.384-\mathrm{xi})}{0.384-0.342}\right)=\left(\frac{2(0.384-0.376)}{0.384-0.342}\right)=0.3810$.

Similar procedure has been followed, $k\left(x_{1}\right), \ldots . . k\left(x_{9}\right)$ found out, from these value

Fade I cycle is calculated as below:

$\mathrm{k}_{\mathrm{b} 1}(\mathrm{x})=\sum_{\mathrm{i}=1}^{9} \alpha \mathrm{ik}(\mathrm{xi})$;

$0.375=0.371=0.362=0.357=0.376=0.384=0.365=0.353=0.342=1 / 9$

Then substituting the values of $\mathrm{k}\left(\mathrm{x}_{1}\right)$ to $\mathrm{k}\left(\mathrm{x}_{9}\right)$ in $\mathrm{Eq}$.(10) we get $\mathrm{k}_{\mathrm{b} 1}(\mathrm{x})=0.4532$. 
On substituting the values as shown in Figure 9 in the Eq. (4), we get $k_{\mu}(x)$ for $\mathrm{NAO} 1$ as $0.3852, \mathrm{NAO} 2$ as 0.3714 and NAO3 as 0.3142 . The dependent function for thickness loss for NAO1 was found as follows:

The thickness loss values $\left(\mathrm{x}_{1}\right.$ to $\left.\mathrm{x}_{4}\right)$ are $3.1,3.4,3.6,3.3$.

$\mathrm{a}=$ minimum thickness loss in the range;

$\mathrm{b}=$ maximum thickness loss in the range

when $a=3.1 ; b=3.6$,

$k(x i)=\left\{\begin{array}{cc}\left(\frac{x i-3.1}{3.35-3.1}\right), & x i \leq 3.35 \\ 1, & x i=3.1 \\ \left(\frac{3.6-x i}{3.6-3.1}\right), & x i \geq 3.35\end{array}\right.$

The $\mathrm{x}_{1}$ is considered in where the value of $\mathrm{x}$ is 3.4 , the value of $\mathrm{x}$ is greater than 3.35 , so Eq. (11) is reframed as:

$\mathrm{k}(3.4)=\left(\frac{3.6-3.4}{3.6-3.1}\right)=0.4$

The dependent function of thickness loss of NAO1 is found using Eq.(6) which is rewritten as:

$\mathrm{k}_{\mathrm{wr} 2}(\mathrm{x})=\sum_{\mathrm{i}=1}^{4} \delta \mathrm{ik}(\mathrm{xi}) ; 3.1=3.4=3.6=3.3$

$=0.6250$

Similarly all the dependent function are found. The dependent function for wear (weight loss and thickness loss) for NAO1 is $\left(k_{w r 1}(x)=0.5000, k_{w r 2}(x)=0.6250\right), \mathrm{NAO} 2$ $\left(k_{w r 3}(x)=0.5500, k_{w r 4}(x)=0.6000\right)$ and NAO3 $\left(k_{w r 5}(x)=0.6000, k_{w r 6}(x)=0.6600\right)$ as obtained from substituting in Eq. (5). Substituting the values in Figure 9 in Eq. (7)

$\begin{aligned} k_{w}(x) & =k_{w r 1}(x)+k_{w r 2}(x) \\ & =0.5+0.6250=0.5625\end{aligned}$

Upon substituting we get $k_{w}(x)$ for NAO1 as 0.5625 , NAO2 as 0.575 and NAO3 as 0.630 . Wear rate should be lower for ideal friction materials, and NAO1 showed such behaviour $[40,41]$.

Finally substituting the desired values obtained from Eq (4 \& 7) in Eq. (8), The typical example of finding $k_{\text {overall }}(x)$ the values obtained are substituted in the Eq. (8) and the typical equation is shown below Eq.(15), for NAO1 $k_{b}(x)=0.3852 ; k_{w}(x)=0.5625$

$$
\begin{aligned}
k_{\text {overall }}(x) & =k_{b}(x)+k_{w}(x)=0.3852+0.5625 \\
& =0.9477
\end{aligned}
$$

We get $k_{\text {overall }}(x)$ for NAO1 as 0.9477 and for NAO2 as 0.9463 , while that for NAO3 is 0.9442 . Higher the $k_{\text {overall }}$, the better the composites. Based on these results NAO1 rank's first and it is superior in quality when compared to NAO2 and NAO3. 